\title{
SUJEITO E SENTIDO: HEGEL, ARISTÓTELES, SAUSSURE \& CHOMSKY
}

\section{Paulo José Silva Valença (UFAL)}

\section{Hegel: o elogio da voz no advento do Espírito}

Hegel caracteriza a linguagem como meio de a Idéia autoreapropriar-se de si. ao cabo de um movimento de auto-alienação levado a seu ponto supremo. qual seja, a Idéia na forma de Natureza, momento a partir do qual a Idéia se vai automanifestando como Sujeito ou lispirito. numa complexa marcha onde se tem por realidade absoluta a Ideia, de modo que, conforme Ilegel, o sentido da história não é outro que nào o da plenitude da Idéia como Saher Absoluto, compreendido como identidade entre a Idéia e o saber acerca dela mesma.

Nesse sentido, o Saber Absoluto. suprema forma de autoconsciéncia. caracteriza-se como a propria essencia do mundo, nà se devendo confundir a autoconsciencia. tal como compreendida por llegel. com a consciencia kantiana. que se apercebe no eixo da sintese intuitiva e categorial. ou com o intelecto ou coisa pensante, em crmos cartesianos 2 , porquanto essas concepções de consciência. segundo llegel, apenas se aplicam a um dos estádios da Idéia, no qual cla se realiza na forma de razão ou intelecto individual. recebendo de Hegel a denominação de espirito subjetivo.

Segundo Hegel, com efeito, importa serem consideradas duas outras formas do Fspirito: o Expirito Objetivo - identificado como o conjunto das "instituliçós fundamentais do mundo humano, isto é, o dircito. a moralidade. a eticidade" - e o Espririto Absoluto

Na filosofia hegeliana, a Idèia é afirmada não apenas como universal substancia. mas também como sujeito, ou Espirito. infenso, no caso. a interpretaçòes de cunho sobrenaturalista.

D) J:SCARTES, René. Meditaçós. 1973, p. 124-36.

ABBBAGNANO. Nicola. Dicionairio de filosofia. 1982. p. 336 . O resumo de Abbagnano assenta no $\$ 486$ da Enciclopédia das créncias filosóficas de llegel. mas precisamente na segunda secçào da Filosofia do Expirito. ou scja. na parte onde se trata do espirito objetivo (cf. HE(iEL, Enciclopédica das crincias filosoficas em compêndio: 1830. 1995, vol. III, p. 278-336). 
compreendendo o "mundo da arte, da religião e da filosofia"t. As três formas do Espírito, de acordo com Hegel, manifestam a Idéia, ou razão infinita, a qual significa, não um objeto ou representação do pensamento humano, mas "o verdadeiro em si e para si, a unidade absoluta do conceito e da objetividade".

A Idéia é tanto a origem quanto a culminação de tudo o que existe, e tudo o que existe não passa de processo de automanifestação da Idéia, a qual se auto-aliena na natureza (o "ser-outro da Idéia", a sua exterioridade ${ }^{6}$ ), auto-retorna no advento do Espírito em suas três formas, para enfim se consumar em si e para si no que Hegel chama de Espírito Absoluto, no estádio em que a Idéia se auto-reconhece e toma, por fim, consciência de que tudo o que há lhe são elementos da própria automanifestação ${ }^{7}$.

No sistema filosófico hegeliano, a linguagem se inscreve no âmbito da forma subjetiva do espírito, constituindo-se como uma determinação do movimento de auto-aproximação da Idéia. Em sendo uma determinação situada na esfera da forma subjetiva, a linguagem precisa ser diferenciada de outras determinações da subjetividade, pois o espírito subjetivo é visto por Hegel sob o crivo da Aufhebung, ou seja, daquilo que Louis Althusser traduz como "ultrapassagemconservando-o-ultrapassado-como-ultrapassado-interiorizado". Isso significa que, no movimento progressivo da automanifestação da Idéia, o espírito subjetivo passa por estádios ou formas, que vão de um nível imediato e não-consciente a um nível mediato e consciente, até o ultrapassamento da própria forma subjetiva e a manifestação do Espírito em sua forma objetiva. Tal como Hegel estabelece no § 387 da Enciclopédia das Ciências Filosóficas, o Espírito Subjetivo fica configurado:

\footnotetext{
4 ABBAGNANO, op. cit., p. 336. Cf. HEGEL, op. cit., p. 339-64.

HEGEL. Enciclopédia das ciências filosóficas em compêndio: 1830. 1995, vol. I, p. 348.

6 Id., op. cit., p. 17.

7 Cf. a esse respeito, além do próprio Hegel: Abbagnano, op. cit., p. 503; ALTHUSSER, Louis. Sobre a relação de Marx com Hegel. In: D'HONDT, Jacques et al. Hegel e o pensamento moderno. 1979, p. 135 6; DERRIDA, Jacques. O poço e a pirâmide: introdução à Semiologia de Hegel. In: D'HONDT, Jacques et al. Op. cit., p. 44-5.

8 ALTHUSSER, op. cit., p. 132.
} 
A) Em si ou imediato. Assim ele é a alma ou o espirito-da-natureza; objeto da ANTROPOLOGIA.

B) Para si ou mediatizado, ainda enquanto reflexão idêntica sobre si e sobre o Outro: o espírito na relação ou particularização. É a consciência, o objeto da FENOMENOLOGIA DO ESPÍRITO.

C) O espirito que se determina em si mesmo, enquanto sujeito para si. É o objeto da PSICOLOGIA."

A consciência, em Hegel, não vai de encontro ao que dela se possa compreender, em termos daquilo que em Kant se entende como upercepção pur $a^{10}$, nem se contrapõe ao que Husserl atribui como o que há de primordial na compreensão do sentido de consciência, a intencionalidade ${ }^{11}$. Kant e Husserl circunscrevem no âmbito da consciência a estruturação de uma polaridade. De uma forma geral, esses dois filósofos subscrevem a noção de que o sujeito transcendental só aparece como ponta de um eixo, cuja outra extremidade é o objeto. É no eixo, pois, da relação sujeito - objeto que o próprio sujeito pensa a si mesmo, não como um objeto, mas como algo que pensa um objeto. Este, por sua vez, não jaz em uma exterioridade relativamente ao sujeito, pois o objeto, para Kant, resulta da síntese das representações a ele dirigidas pelo sujeito transcendental: para Husserl, o objeto é algo implicado pelo próprio estatuto da intencionalidade do ato de consciência, ou seja, o ato no

"HEGEL, 1995, vol. III, p. 37.

11 Segundo Kant. há de distinguir-se a apercepção pura da empirica, pois, ao passo que esta acompanha cada uma das representações, aquela consiste em algo distinto da sensibilidade, não resulta da sintese de representações do sujeito transcendental, não pode ser representada. mas se instaura a si mesma como consciência reflexa e capaz de efetivar a sintese das representaçòes. Assim, a apercepçào pura "é aquela autoconsciência que, ao produzir a representação eu penso, que tem de poder acompanhar todas as outras, e que é una e idêntica em toda a consciência, não pode ser acompanhada de nenhuma outra" (KANT, Crítica da razão pura. 1989, p. 131).

1 A respeito, cf. BORDINI, Maria da Glória. Fenomenologia e Teoria Literirita, 1990, p. 32-6, onde lemos a tradução de Bordini acerca das palavras de Lévinas, segundo as quais a consciência, para Husserl, consiste em "um dominio primeiro que torna possivel e compreensivel um 'objeto'e um 'sujeito' - termos já derivados”. 
qual a subjetividade se inscreve conjuntamente com uma objetividade: em Husserl, o sujeito não precede, como consciência, o objeto ${ }^{12}$.

Hegel assume essa verdade da consciência comum a Kant e a Husserl, ao defini-la como "o espírito em relação". Mas, enquanto estes visam o sujeito no campo de uma transcendentalidade. fazendo a subjetividade concernir ao âmbito da consciência, sem se proporem considerar algo além do eixo sujeito-objeto, Hegel coloca a consciência como estádio dentro da subjetividade, ou Espirito Subjetivo, que, como um todo, é elemento passageiro na marcha da automanifestação da Idéia a culminar na identidade do em si e do para si desta mesma Idéia. O que subsiste. para Hegel, na propriedade do "espírito em relação" está ainda vinculado a uma exterioridade - qual seja, a do objeto - não inteiramente suprassumida.

Ao prestarmos atenção ao terceiro estádio da subjetividade, como o formulara Hegel, observamos que a consciência, nesse momento, já se encontra ultrapassada, pelo menos na forma kantianohusserliana de relação explicitada como polaridade entre sujeito e objeto. O terceiro estádio da subjetividade é, de acordo com Hegel, a determinação do sujeito como elemento em si e para si, ou seja, efetiva-se a superação do objeto como condição sine qua non da apercepção. Desse modo, O Espírito Subjetivo está, ele mesmo, pronto para ser superado como estádio puramente ideal, interior da Idéia, fazendo-se já anunciar o advento de outra forma, a do espirito "na forma da realidade como [na forma] de um mundo a produzir e produzido por ele, no qual a liberdade é como necessidade presente. [É o] espírito objetivo"13.

12 Em Husserl, por mais que seja acentuada a primordialidade da consciência, a ponto de esta preceder, tornando-os possivecis e compreensiveis um "objeto" e "um sujeito" (cf. LÉVINAS, Emmanuel. Théorie de l'intuition dans la Phénoménologie de Husserl. 1978, p. 64). permanece extremamente encarecido o pólo sujeito da relaçãó sujeitoobjeto, dado que a consciência não está do lado de um mundo, do qual Husserl não nega a existência como anterior à consciência, mas do sujeito transcendental que garante a certeza de esse mundo existir com efeito, tal como o $\$ 49$ de Ideas deixa ver (cf. HUSSERL, Edmund. Ideas: general introduction to pure phenomenology. 1976, p. 150-4).

13 HEGEL, 1995, vol. III, p. 29. 
Para Hegel, nem o sujeito transcendental, com as implicações de uma objetividade sempre relativa a una subjetividade, nem uma forma de sujeito em si c para si são o elemento final de uma cadeia. não se caracterizando a filosofía hegeliana como um avatar do subjetivismo antropológico. De acordo com o pensamento deste filósofo, se há um sujeito como origem e fim de tudo. esse sujeito é a Ideia. que, infensa a tudo se the venha opor, mesmo a título de objeto para ela. não se confunde com uma subjetividade pensante individual, nem com o sujeito epistêmico da ciência. Essas duas formas de subjetividade, nos cânones do pensamento hegeliano, não passariam de éstádios ou manifestações superáveis da Idéia, podendo-nos servir. lalvez. nesse sentido, um excerto de Louis Althusser, para explicarnos a intenção hegeliana de estabelecer a Idéia como elemento último em si e para si de una marcha, na qual o estádio do Espirito Subjetivo se mostra como passageiro:

Enuncia-se: a História è um processo de alienação sofrido por um sujeito e esse sujeito è o homem.

Ora, como muito bem o notou Jean Hyppolite, nada é mais estranho ao pensamento de Hegel do que esta concepção antropológica da História. Para Hegel, a História é um processo de alienação, mas este processo não tem o homem por sujeito.

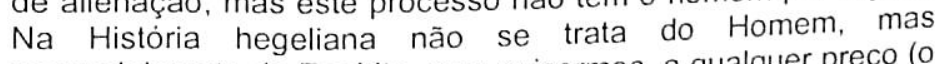
essencialmente do Espirito, e se quisermos, a qualquer preço (o que em relação ao sujeito è aliảs falso) um "sujeito" na História, é dos "povos" que será preciso falar, ou mais exatamente (e aqui nos aproximamos da verdade) é dos momentos do desenvolvimento da Idéia tornada Espirito. [...] a História não e a alienação do Homem, mas a alienação do Espirito, isto è, o último momento da alienação da Idèia."

Em todo caso. Hegel assinala um lugar para a subjetividade na forma de Espirito Subjetivo, procurando caracterizá-la e estabelecerthe o limiar de superação: o estádio do espirito "que se determina em si mesmo enquanto sujeito para si. É o objeto da PSICOLOGIA". E, nesse estádio no qual a subjetividade se auto-afeta. em que ela se autoenvia ao campo da interioridade - aliás, em que ela funda esse campo - estabelece-se, de acordo com Hegel, a excelência do ouvir-se falur. Para o Autor de A Fenomenologia do Espirito, o valor da palava sonora decorre do fato de ela, malgrado ressoar na exterioridade. reportar-se quase que instantaneamente à interioridade do sujeito.

1. AI.THUSSER, 1979, p. 133 


\section{O empreendimento semiológico hegeliano: o primado do som, e o signo nos domínios da psicologia}

A proposição hegeliana do "espírito determinando-se a si e em si mesmo como sujeito para si" concorda. efetivamente. com o que Hegel compreende como a atividade do ouvir-se falur, na qual o sujeito se auto-afeta por meio do elemento fono-subjetivo, para o qual não tenham de subsistir, para além da percepção sensivel, quaisquer instâncias sensiveis como tais, dado que o som vocal. conforme o pensamento hegeliano, pode ser interiorizado pelo ouvido, órgão por excelência, de acordo ainda com Hegel, da idealidade que. em seu mais alto grau, não significa outra coisa, senão a interioridade, ou marca do espirito em seu estádio subjetivo.

$\mathrm{Na}$ Estética, Hegel estabelece uma hierarquização dos sentidos corporais, entre eles havendo destaque para a vista e o ouvido, como os únicos apropriados ao interesse teórico que deixa permanecerem as coisas na sua liberdade ${ }^{15}$. Os demais sentidos - tato. paladar e olfato - são excluídos, do ponto de vista de poderem vir a desempenhar função cognitiva ${ }^{16}$, principalmente $\mathrm{em}$ se tratando da compreensão da obra de arte, cuja finalidade é "a educação para a verdade através da forma sensivel", conforme algumas palavras sintetizadoras de Nicola Abbagnano acerca do pensamento de Hegel sobre a arte ${ }^{17}$. Pelo fato de a verdade, para Hegel, ser a resposta da objetividade ao conceito, a verdade é a própria Idéia, que é. em seu télos. auto-identidade no seu auto-saber - ou seja, no seu conceito ${ }^{18}$. Portanto, para o pensamento hegeliano, o estetismo é absolutamente

1' Para Hegel, a essência do espirito é a liberdade absoluta. que consiste não apenas em uma autonomia relativamente ao Outro, mas em uma vitória sobre este. A liberdade se efetiva como auto-identidade, não fazendo parte dela a diferenciação, a não ser como fase ou estado passageiro. A esse respeito, merece leitura o $\$ 382$ da Enciclopédia, com seu respectivo adendo (cf. HEGEL, 1995, vol. III, p. 23-4).

HEGEL, Estética. 1993, p. 347.

ABBAGNANO, 1982, p. 354.

"A idéia é o verdadeiro ém si e para si, a unidade absoluta do conceito e da objetividade. Seu conteúdo ideal nào é outro que o conceito em suas determinações, seu conteúdo real é somente a exposição do conceito, que ele se dá na forma de um ser-ai exterior; e estando essa fïgura excluida na idealidade do conceito, na sua potência, assim se conserva na idéia" (HEGEL, 1995, vol. I, p. 348). 
condenável, por pretender fixar a finalidade da obra de arte na fruição, em si e para si, do objeto sensivel: a obra artística, segundo Hegel, não pode usurpar o para si definitivo, que só cabe à Idéia. Tudo o que existe é manifestação da e para a Idéia, o que significa que tudo é passageiro na marcha teleológica que leva à autocontemplação da Idéia, como forma suprema de autoconsciência.

Em sendo, pois, a Idéia a origem e a finalidade de todo processo de manifestações, compreende-se que ela é, desde sempre, uma presença, da qual a auto-identidade, na forma superior de autoconsciência, não passa de auto-reapropriação definitiva. Desse modo, as manifestações anteriores à auto-reapropriação definitiva da Idéia constituem-se como o diferir da presença - diferir no seu duplo sentido de adiar e differenciar, pois nenhuma dessas manifestações é idêntica à Idéia, ou melhor, não ainda, por conta de a identidade da Idéia sobrevir como auto-identidade, da qual toda e qualquer diferenciação se veja finalmente excluída pelo autoconhecimento da Idéia que reúne como indiferenciado de si aquilo que antes the parecia como diferenciado.

As manifestações da Idéia, enquanto diferenciações e adiamentos da presenç̧a - conquanto, como o parágrafo anterior deixara ver, não se devam tomar diferenças em sentido radical ou absoluto -, podem ser compreendidas sob o estatuto de signos da Idéia. Nesse caso, concordamos com a seguinte explanação da parte de Jacques Derrida:

O signo, diz-se correntemente, coloca-se em lugar da coisa mesma, da coisa presente, "coisa" equivalendo aqui tanto ao sentido como ao referente. O signo representa o presente na sua ausência. Faz as vezes dele. Quando não podemos tomar ou mostrar a coisa, digamos o presente, o ente-presente, quando o presente não se apresenta, então significamos, servimo-nos do subterfúgio de um signo. Significamos. O signo seria então a presença diferida. [...] o signo, diferindo a presença, só é pensável a partir da presença que ele difere e em vista da presença diferida de que intentamos reapropriarnos. $^{19}$

A caracterização das manifestações da Idéia como signos desta última se coaduna com a proposta hegeliana da atividade do Espírito como emancipação do estádio da natureza, ou ser-outro da

19) DERRIDA, Jacques. Margens da filosofia, 1991. A diferença, p. 40. 
Ideia. Forma suprema da auto-alienação da Idéia, a Natureza vem solier uma forma de negação da parte do Espirito. quando este. arbitrariamente. pòe o signo. Conforme llegel estabelece, na Enciclopédia da Propedèutica,

A representação, tendo-se libertado da realidade presente exterior e tornada subjectiva, esta realidade e a representação interna são colocadas face a face, como duas coisas distintas. Uma realidade exterior torna-se signo quando è arbitrariamente associada a uma representação que não the corresponde e se distingue dela mesmo [sic] pelo seu conteúdo, de tal maneira que esta realidade deve ser a sua representação ou significação. ${ }^{20}$

A arbitrariedade requerida por Ilegel para o signo tem relaçào necessária com a liberdade própria do lispirito que, ultrapassando o estádio inicial da alienação suprema da Idéia no séu ser-outro a Natureza -, vai por tim recolher a lição de que esta liberdade mesma é da ordem da necessidade da Idéia. Assim, aquilo yue se mostrava como arbitrário se revela por fïm como necessário: a Natureza não é um reino à parte do espírito ou da Idéia. mas a Idéia. ainda que alienada de si mesma. A Natureza, pois, negação da autonomia da Idéia. nào passa de autonegação da Idéia que, negando a Natureza. auto-atirma-se. suprassumindo a negação anterior.

Ao estabelecer a associação arbitrarira como condição sine quu nom do signo. Hegel se está reportando à ação do espirito subjetivo encuanto promotor da representação contraposta à intulção sensivel. Isso significa que a associascaio arbitraria identifica o estadio da superação da Natureza. forma exterior da Idéia. ou scja. a Idéla, a partir he seu ser-sutro (a Natureza). de sua máxima auto-exterioridade.

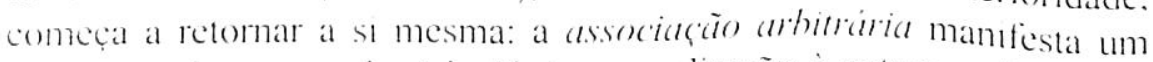
passo a mais na marcha teleológica. em direção a autoconsciência ou auto-inteligibilidade da Idéia. Devemos, pois. entender o auto-retorno da Idéra como um movimento de superação da Natureza. da exterioridade sensivel, que não é totalmente suprimida, mas interiorizada pela ação do Espírito, que não recolhe de forma passiva os dados da intuição sensivel, mas thes perscruta o sentido, ordena-lhes a ocorrència, tenta apreender-lhes a razão de ser. a sua essência, aquilo

Ilegel apud DERRII)A, Jacques. O poço e a piramide: introduçào à Semiologia de Hegel. In: DolJovint. Jacques at alii. Hegel a " pensamento moderno. 1979, p. 68. 
que os faz subsistir, ou mesmo existir, sendo que a manifestação desse sentido ou essência somente se consumará no advento do Espírito Absoluto, que é a Idéia em sua realidade autoconsciente.

A representação visual é uma forma de signo, através da qual os dados puros e imediatos da intuição sensível são organizados sob a instância do Espirito, que lhes impõe tanto a organização quanto thes advinha a possibilidade de ocorrência e lhes capta a unidade em meio à diversidade em que e como ocorrem. Entretanto, esses dados, sob a forma de representação visual. não são suscetiveis de completa interiorização pelo Espírito, pois perduram além da percepção. mantendo-se como que resistentes ao recolhimento ideal, jazendo, de alğum modo e apesar da atividade de interiorização característica do lispirito, na exterioridade.

Em se tratando da representação sonora, porém. o Espírito não somente age sobre o dado sensivel, promovendo-lhe a intelecção, como ¿ auto-afetado pela voz, que é automanifestação do abalo interior do corpo perante os dados da intuição sensível. Em outras palavras, o sujeito se ouve falar, e, nesse movimento, recolhe em si a intelecção do objeto e a própria auto-exteriorização pela voz. Nesse ouvir-se falur. termina apagando-se o elemento natural (o som). que mantém a voz participante da exterioridade radical da Idéia, da Idéia em seu ser-outro (a Natureza). auto-alienada. Com isso, a representação sonora subsiste completamente relevada na interioridade do sujeito. Fla. pois, mais do que qualquer outra forma de representação, realiza aquilo mesmo que fà da representação o que esta é, de acordo com Hegel:

A representação, enquanto intuição rememorada [erinnerte], è o meio termo entre o "achar-se-determinado" imediato da inteligência, e a inteligência em sua liberdade, o pensar. Para a inteligência a representação è o seu, ainda com subjetividade unilateral; enquanto esse "seu" ainda está condicionado pela imediatez, não é, nele mesmo, o ser. O caminho da inteligência nas representaçōes consiste tanto em interiorizar a imediatez em pôr-se intuicionante em si mesma - quanto em suprassumir a subjetividade da interioridade, e em extrusar-se dela [e] nela mesma e em ser em si mesma na exterioridade própria dela. Mas, enquanto o representar começa da intuição e de seu material achado, essa atividade está ainda afetada pela diferença, e suas produções ainda são nela sinteses, que só no pensar se tornam a imanência concreta do conceito. ${ }^{21}$

21 HEGEL, 1995, vol. III, p. 234-5. 
Percebemos que Hegel assinala uma deficiência na representação, por conta dos laços que esta mantém com a exterioridade. Mesmo assim, não fica difícil entendermos que o signo sonoro se caracteriza como a forma mais perfeita de representação, a ponto de ele consumar o ideal do próprio signo em geral, pois, conforme esclarece Jacques Derrida acerca dos estatutos hegelianos do signo, este pode ser

compreendido segundo a estrutura e o movimento da Aufhebung pela qual o espirito, elevando-se acima da natureza na qual está submerso, suprimindo-a e retendo-a simultaneamente, sublimando-a em si mesmo, se realiza (s'accomplit) como liberdade interior e se apresenta assim a si mesmo, como tal. ${ }^{22}$

A determinação subjetiva do signo torna-o objeto da Psicologia, o que não significa o confinamento do signo no território de uma subjetividade individual a fetada pelos fenômenos externos. Na realidade, a Psicologia como território no qual o signo encontra seus estatutos diz respeito, de acordo com o pensamento hegeliano, a uma ciência do "espírito que se determina em si mesmo, enquanto sujeito para si"23. Portanto, essa Psicologia ultrapassa o âmbito daquilo que Hegel chama de Fenomenologia do Espírito, que diz respeito ao espírito na forma de subjetividade determinada pelo vínculo transcendental - no sentido kantiano - com o objeto. A Psicologia, que se ocupa do "espirito que se determina em si mesmo, enquanto sujeito para si”, é, propriamente falando, uma psicologia racional.

A psicologia racional, cujos fundamentos remontam a Aristóteles, caracteriza-se por considerar que a alma não se identifica somente como a forma da consciência enquanto relativa ao objeto, ou seja, como a consciência conforme Kant a compreendera. De acordo $\mathrm{com}$ a psicologia racional, a alma possui não somente o atributo da consciência, mas também o da substancialidade, o da simplicidade, o da unidade e o da possibilidade de relações com o corpo. Em outras palavras, a alma é uma realidade em si, indivisível e distinta do corpo, do qual a tradição aristotélica a reconhece como inseparável.

Até Kant, essa concepção de alma, notadamente no que respeita ao aspecto da substancialidade, manteve-se quase que

\footnotetext{
22 DERRIDA, 1979, p. 49.

23 HEGEL, 1995, vol. III, p. 37.
} 
inalterada. De certo modo, podemos constatar que o conceito de consciéncia - como "totalidade ou mundo da experiência interna" ${ }^{24}-$ vai aos poucos, de Descartes em diante, absorver o "conceito tradicional de alma" 25 , mas nem Descartes, nem Leibniz, nem Spinoza deixam de lado o aspecto de realidade em si da alma, reconhecendo-a como substância. Na verdade, será David Hume quem, no século XVIII, provocará um abalo na concepção tradicional da alma como substância ou realidade em si, com a sua proposta atomísticopsicológica, segundo a qual "a realidade substancial, seja a da alma, ou do eu, é uma construção fictícia. que parte das relações de semelhança e da causalidade das percepções entre si" ${ }^{20}$.

Por finm, a substancialidade da alma - como, aliás, qualquer substancialidade - virá a ser duramente criticada por Kant, para quem a noção de substância não passa de categoria do entendimento, não podendo significar, com isso. um atributo que subsista além das próprias operações do entendimento, ou seja, da faculdade dos conceitos ${ }^{27}$. Para Kant, as categorias do entendimento dizem respeito

\footnotetext{
24 ABBAGNANO, 1982, p. 29.

25 Ibid.

20 Hicl.
}

27 Para Kant, o diverso sensivel sofre a síntese das representaçòes do entendimento - ou faculdade dos conceitos, capaz de efetivar o conhecimento -, através de doze categorias, correspondentes às formas lógicas dos juizos. Um objeto, sob o crivo da sintese categorial, define-se como aquilo em cujo conceito se unifica o múltiplo de uma intuição dada. Quanto aos juizos, lembremos que podem ser: 1) quanto à quantidade, ou seja, à extensão de sua validade: a) singulares, cuja formulação pode ser expressa como "este S (sujeito) é P (predicado)"; b) particulares, com a formulação "alguns S são P"; c) universais ("todos os S são P"); 2) quanto à qualidade: a) afirmativos ( $\mathrm{S}$ é $\mathrm{P}$ ); b) negativos (S não é $\mathrm{P}$ ); $\mathrm{c}$ ) indefinidos ou limitativos ( $\mathrm{S}$ é um não-P); 3) quanto à relação entre as representações veiculadas: a) categóricos ( $\mathrm{S}$ é $\mathrm{P}$ ); b) hipotéticos (se $\mathrm{S}$ é $\mathrm{P}$. não é $\mathrm{Q}$ ); disjuntivos ( $\mathrm{S}$ é ou $\mathrm{P}$ ou $\mathrm{Q}$ ); 4) quanto à modalidade, isto é, seu valor cognitivo: a) problemáticos ( $\mathrm{S}$ é talvez $\mathrm{P}$ ); assertóricos ( $\mathrm{S}$ é $\mathrm{P}$ ); c) apodícticos ( $\mathrm{S}$ é necessariamente $\mathrm{P}$ ). O sistema das categorias kantianas corresponde simetricamente a essas classes de juizos: 1) quantidade: a) unidade, b) pluralidade, c) totalidade; 2) qualidade: a) realidade, b) negação, c) limitação; 3) relação: a) substância-acidente, b) causa-efeito, c) ação recíproca; 4) modalidade: a) possibilidade, b) existência. c) necessidade. A forma como Kant expõe suas categorias é rigorosamente 
precisamente à relação sujeito-objeto, o que implica, entre outras coisas, a impossibilidade de acedermos a realidades em si. independentes do sistema da consciência, compreendida como uma determinação transcendental que torna possivel a apercepção do sujeito apenas como um dos pólos da relação cognitiva sujeitoobjeto $^{28}$. No tocante ao aspecto ou atributo da substancialidade da alma, Kant é categórico:

pode-se certamente admitir a proposição $A$ alma é uma substância, se nos resignarmos a que este nosso conceito não leve mais além ou não possa ensinar nada das conclusões habituais da doutrina racional da alma, como, por exemplo, a duração constante da alma em todas as modificaçōes e mesmo na morte do homem e que, portanto, designa apenas uma substância na idéia, mas não na realidade. ${ }^{29}$

Em Hegel, a alma passa a ser identificada como espirito suhjetivo. ou seja. como automanifestação da Idéia no plano da interioridade. Em sendo uma forma de automanifestação da própria Idéia, a alma não pode prescindir do aspecto da substancialidade. sem que Ilegel venha a separar. todavia, esse aspecto daquilo que podemos chamar de referencia a consciéncia. Na realidade, segundo o fílósofo alemão. a alma é já o elemento inaugural de um movimento de autoconsciência, entendida esta como a união do conceito e da objetividade. Tal movimento culmina justamente no advento da Idéia como espirito absoluto, como autoconsciência definitiva em $\mathrm{si}^{33)}$.

Fim retomando a noção tradicional de substancialidade da alma. Hegel pretende ir além dos limites que Kant impusera à filosofia, ou seja, os limites que caracterizam qualquer afirmação acerca de realidades em si como extrapolações das categorias do

sistemática. O primeiro termo de cada uma das quatro classes em que as categorias se agrupam triadicamente exprime uma condiçào: o segundo, o condicionado; o tercerro, o conceito que resulta da união da condição e do condicionado. Assim, por exemplo, a unidade é a condição da pluralidade, e a pluralidade considerada como unidade é totalidade (KANT, Critica da razäo) pura. 1989, p. 103-15).

thid. p. $110-11$.

Ihid., p. 333.

"A idéia é o verdadeiro em si e para si, a unidade absoluta do conceito e da objetividade. $[\ldots \mid$ a idéia é antes de tudo, somente a substância una, universal." (HEGEL, 1995, vol. I, p. 348). 
entendimento, como paralogismos da razão. Dessa forma, enquanto Kant estabelece que a substância não passa de categoria do entendimento, o que retira do pensamento o status de substância pensante, dá-se, com Hegel, que o pensamento - ou melhor, a razão é substância, tem realidade em si.

Para Kant, a consciência não se caracteriza como algo além da determinação sujeito-objeto, o que significa dizer que o sujeito apenas se percebe como relativo ao objeto, ou seja:

A consciência própria está, pois, ainda bem longe de ser conhecimento de si próprio, não obstante todas as categorias que constituem o pensamento de um objeto em geral pela ligação do diverso numa apercepção. Assim como para conhecer um objeto distinto de mim, além de pensar um objeto em geral (na categoria) ainda preciso de uma intuição para determinar esse conceito geral, assim também, para o conhecimento de mim próprio, além da consciência ou do facto de me pensar, careço ainda de uma intuição do diverso em mim, pela qual determine esse pensamento; e existo como uma inteligência simplesmente consciente da sua faculdade de sintese, mas que, em relação ao diverso que deverá ligar, estando submetida a uma condição restritiva que se chama o sentido interno, só pode tornar intuivel essa ligação segundo relaçōes de tempo completamente estranhas aos conceitos próprios do entendimento, segue-se dai que essa inteligência só pode conhecer-se tal como aparece a si mesma com respeito a uma intuição (que não pode ser intelectual nem ser dada pelo próprio entendimento) e não como se conheceria se a sua intuição fosse intelectual. ${ }^{31}$

Para Hegel, a consciência se caracteriza como uma das formas pelas quais a Idéia começa seu auto-retorno. Na realidade, a consciência, tal como Kant a define, sob a ótica da transcendentalidade, é o próprio espírito subjetivo "para si ou mediatizado, ainda enquanto reflexão idêntica sobre si e sobre o Outro: o espírito na relação ou particularização". E, de acordo com o fílósofo de Iena, a consciência não pode permanecer como a forma última do espírito, assim como não se pode tolerar que a Idéia admita a transcendentalidade da relação sujeito-objeto como insuperável:

3 KANT, Critica da razão pura. 1989, p. 160. 
A experiência que a consciência faz sobre si mesma não pode abranger nela, segundo seu conceito, nada menos que o sistema completo da consciência ou o reino total da verdade do espirito [...].

A consciência, ao abrir caminho rumo à sua verdadeira existência, vai atingir um ponto onde se despojará de sua aparência: a de estar presa a algo estranho, que é só para ela, e que é como um outro. Aqui a aparência se torna igual à essência, de modo que sua exposição coincide com esse ponto da ciência autêntica do espirito. $E$, finalmente, ao aprender sua verdadeira essência, a consciência mesma designará a natureza do próprio saber absoluto. ${ }^{32}$

Em se tratando da ultrapassagem do estádio da consciência como relativa ao eixo sujeito-objeto, Hegel estabelece uma fase seguinte, em que o espírito mesmo se recolhe em si, autoreconhecendo-se em si como sujeito para si. Nessa fase. ocupa um papel de suma importância o fenômeno da auto-audição estabelecido como marca do signo sonoro. Por conta do valor concedido ao signo como elemento necessário à auto-reapropriação da Idéia, Hegel traça o percurso de uma teoria do signo, ou Semiologia, no âmbito da Filosofia do Espírito - mais precisamente, conforme já referido, no setor que, em tal território, diz respeito à forma subjetiva do Espirito. Dentro desse setor, convém reafirmarmos que a teoria do signo faz parte da divisão reservada ao enfoque e tratamento do "espirito que se determina em si mesmo, enquanto sujeito para si", ou seja, não mais na forma anterior de consciência como relação entre sujeito e objeto ${ }^{33}$. A Semiologia, do ponto de vista hegeliano, faria parte da Psicologia.

HEGEL. Fenomenologia do Espirito. 1992, vol. I, p. 72-3.

Essa ultrapassagem do estádio do espirito como consciência, tal como tratado pelo criticismo kantiano, talvez explique o lugar especial concedido por Hegel à linguagem. Ou seja, o fato de Kant não admitir o ir além da relação transcendental sujeito - objeto impede que se venha a considerar a linguagem que, a par de sua interioridade subjetiva, $t \mathrm{em} \mathrm{em}$ si o aspecto de exterioridade. Em outras palavras, suspeitamos que Kant não tenha sabido como enfrentar o problema da linguagem, por conta de esta comportar o aspecto da exterioridade relativamente ao eixo da relação transcendental. Para este aspecto, todavia, Hegel proporá a Aufhehung no modo do ouvir-se falar que, se, por um lado, é voz a ressoar na exterioridade, por outro, não the permite a permanència nesta exterioridade, mas the assinala como característica o apagamento no autoenvio da voz pelo sujeito por conta de este se auto-escutar. 
Com efeito, na Enciclopédia das Ciências Filosóficas, a teoria do signo se inscreve no âmbito da Filosofia do Espirito, ou seja, na terceira parte da obra, precedida pela Ciência da Lógica e pela Filosofía da Natureza ${ }^{34}$. Instância ou produção do auto-retorno da Idéia, o signo tem seu lugar, mais precisamente, na primeira fase da Filosofia do Espirito, cuja articulação efetiva-se da seguinte forma, segundo Hegel, no 385 da Enciclopédia:

O desenvolvimento do espirito é este:

$\left.1^{\circ}\right)$ O espirito é na forma da relação a si mesmo: no interior dele the advém a totalidade ideal da idéia. Isto é: o que o seu conceito é, vem-a-ser para ele; para ele, o seu ser é isto: ser junto de si, quer dizer, ser livre. [É o] espirito subjetivo.

$2^{\circ}$ ) [O espirito é] na forma da realidade como [na forma] de um mundo a produzir e produzido por ele, no qual a liberdade é como necessidade presente. [É o] espirito objetivo.

$3^{\circ}$ ) [O espírito é] na unidade - essente em si e para si e produzindo-se eternamente - da objetividade do espirito e de sua idealidade, ou de seu conceito: o espírito em sua verdade absoluta. [É o] espirito absoluto. ${ }^{35}$

O lugar da Semiologia advém de uma repartição no cerne da primeira forma do espírito, ou seja, ela se inscreve no âmbito do espirito subjetivo, sendo que este se constitui articuladamente em três fases:

A) Em si ou imediato. Assim ele è a alma ou o espiritoda-natureza; objeto da ANTROPOLOGIA.

B) Para si ou mediatizado, ainda enquanto reflexão idêntica sobre si e sobre o Outro: o espirito na relação ou particularização. É a consciência, o objeto da FENOMENOLOGIA DO ESPIRITO.

C) O espirito que se determina em si mesmo, enquanto sujeito para si. É o objeto da PSICOLOGIA. ${ }^{36}$

34 Eis a divisão proposta por Hegel para a Ciência do Espírito:

I - A lógica, a ciência da idéia em si e para si;

II - A Filosofia da Natureza, como a ciência da idéia em seu ser-outro;

III A Filosofia do Espirito, enquanto idéia que em seu ser-outro retorna a si mesma.

(HEGEL, 1995, vol. I, § 18, p. 58).

is HEGEL, 1995, vol. III, p. 29.

3) Ibid., p. 37. 
A autodeterminação em si e para si da subjetividade, segundo Hegel, efetiva-se no ouvir-se falar, autopresença máxima da Idéia em sua forma de espírito subjetivo. A palavra sonora, medium em que se realiza a auto-afecção da parte da subjetividade, não poderia deixar de auferir, no pensamento hegeliano, de primazia sobre quaisquer outras modalidades de representação, sendo que, por conta de sua relatividade à palavra sonora, a escrita alfabética recebe de Hegel o elogio e a justificação ${ }^{37}$ :

A escritura alfabética é em si e para si mais inteligente: nela a palavra - [que è] o modo, peculiar à inteligência, mais digno para exteriorizar suas representações - é trazida à consciência, constituida em objeto da reflexão. [...] aprender a ler e escrever uma escrita alfabética deve considerar-se como um meio de cultura infinito, não bastante apreciado, já que conduz o espirito do sensivelmente concreto à atenção para com o formal, à palavra sonora e aos seus elementos abstratos, e faz algo essencial [que é] fundar e deixar limpo no sujeito o solo da interioridade. $^{38}$

\section{Subjetividade e sentido: os contornos hegeliano-aristotélicos da Lingüística}

A primazia da voz e da palavra sonora - base do privilégio concedida à escrita alfabética --, bem como a inserção da Semiologia no campo da Psicologia põem Hegel e Saussure no caudal de uma tradição que remonta a Aristóteles, que dedicou à voz um lugar especial no tratado Peri Psychês, assim como, no De interpretatione, "definiu os signos, os símbolos, a palavra e a escrita, a partir dos pathemata tes psychês", ou afecções de alma".

O estudo de Jacques Derrida sobre a proposta semiológica de Hegel merece nosso apoio, desde que saibamos reconhecer que a critica derridiana do privilégio da oralidade somente se justifica em termos de um reducionismo da própria palavra sonora ao àmbito de uma racionalidade fechada em si mesma, da qual a visão de uma subjetividade auto-suficiente e autojustificadora vem a ser o corolário natural (Cf. DERRIDA, 1979)

is HEGEL, 1995, vol. III, p. 251-2.

3." DERRIDA, 1979, p. 47. 
Nesse sentido, Hegel não deixa de ser bastante explícito no tocante à importância que se deve atribuir ao legado da Psicologia de Aristóteles:

Os livros de Aristoteles sobre a alma, com seus tratados sobre os aspectos e estudos particulares da alma, são por esse motivo ainda sempre a mais notável ou única obra de interesse especulativo sobre esse objeto. O fim essencial de uma filosofia do espirito só pode ser reintroduzir o conceito no conhecimento do espirito; e, com isso, reabrir também o sentido daqueles livros aristotélicos. ${ }^{40}$

Saussure não deixa de explicitar, no Curso de Lingüistica Gercal, a dependência entre a Semiologia - por extensão, a Lingüística - e a Psicologia:

$\mathrm{Na}$ realidade, tudo é psicológico na lingua inclusive suas manifestaçōes materiais e mecânicas, como a troca de sons; e já que a Lingüistica fornece à Psicologia social tão preciosos dados, não faria um todo com ela? ${ }^{41}$

Pode-se, então, conceber uma ciência que estude a vida dos signos no seio da vida social, ela constituiria uma parte da Psicologia social e, por conseguinte, da Psicologia geral; chamá-la-emos de Semiologia [...]. A Lingüistica não é senão uma parte dessa ciência geral $[\ldots]_{2}$. Cabe ao psicólogo determinar o lugar exato da Semiologia.

Além disso, malgrado estabeleça que a "língua não constitui, pois, uma função do sujeito falante ${ }^{,+3}$, Saussure conclama a subjetividade, quando trata da analogia:

a analogia é de ordem gramatical, ela supõe a consciência e a compreensão de uma relação que une as formas entre si. [...].

Por conseguinte, tudo è gramatical na analogia, acrescentemos, porèm, imediatamente, que a criação, que the constitui o fim, só pode pertencer, de começo, à fala, ela é obra ocacional de uma pessoa isolada. ${ }^{44}$

A vinculação entre Lingüística e Psicologia é responsável pelo alinhamento ou configuração envolvendo a língua, o sujeito e o

\footnotetext{
4) HEGEL, op. cit, p. 9.

+1 SAUSSURE, Ferdinand de. Curso de Lingüistica Geral. 1973, p. 14.

t. Ibicl., p. 24.

ti Ibid., p. 22

th Ibid., p. 191-2.
} 
sentido. Com relação a esse último, por exemplo, o saussurianismo jamais deixou de considerá-lo explícita e enfaticamente, como se pode constatar a partir da própria noção de signo lingüístico, entidade de duas faces, que Saussure ${ }^{45}$ representa pela figura:

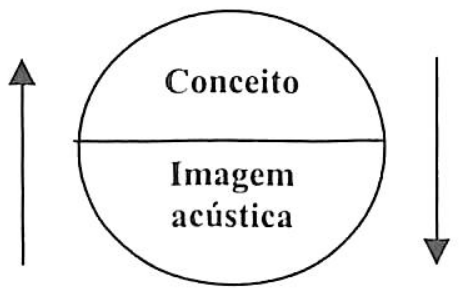

Todavia, na Lingüística contemporânea, o sujeito e o sentido não estão envolvidos apenas na vertente saussuriana, pois o gerativismo chomskyano é bastante caudatário do postulado de uma espécie de subjetividade universal, que Chomsky não deixa de associar a possíveis estruturas inatas do indivíduo ${ }^{46}$, sendo oportuno lembrar que as insurgências da subjetividade no projeto da Gramática Gerativa estão geralmente implicadas pelas questões envolvendo o sentido, conforme assinala Paul Henry a respeito:

Assim, segundo Lakoff, uma frase como: O cachorro acha que o gato é meu pressupõe que os cachorros possam pensar. Se partilhamos essa opinião, a frase será julgada gramatical, senão ela será declarada agramatical. A noção de gramaticalidade está portanto assujeitada à subjetividade individual, dependendo das crenças, opiniōes, convicçōes, conhecimentos, etc [...] que cada um partilha ou não. ${ }^{4}$

Embora se verifique ter havido inicialmente, em termos do projeto gerativista, uma recusa a quaisquer vínculos entre a caracterização da gramaticalidade das sentenças e o conhecimento de mundo partilhado pelos falantes-ouvintes reais, Chomsky, a fim de explicar o caráter de agramaticalidade de algumas sentenças, introduziu a noção de restrições de seleção, por meio da qual, por exemplo, numa sentença com o verbo pensar, ficam estabelecidos, para o sintagma nominal à esquerda, os traços seletivos [+ animado] e [+ humano], o que torna agramaticais frases como:

\footnotetext{
45 SAUSSURE, op. cit., p. 80.

46 HENRY, Paul. A ferramenta imperfeita. 1992, p. 43-55.

47 Ibid., p. 53.
} 
(a) O falecido pensa em Deus.

(b) A planta pensava no jardineiro.

Para Chomsky, as restrições de seleção fazem parte do componente sintático da lingua, ou seja, daquele nível no qual o conhecimento de mundo partilhada pelo sujeito não interfere e que torna possivel a geração de todas as sentenças de uma língua ${ }^{48}$.

Em se tratando, porém, conforme o posicionamento de I.akoff, das frases (a) e (b), por exemplo, basta que haja um conhecimento de mundo partilhado pelos interlocutores quanto a falecidos e plantas poderem pensar, e a gramaticalidade passa a ser reconhecida para tais frases, interferindo, por conseguinte, um consenso entre sujeitos numa decisão anteriormente apenas à mercê do componente sintático.

Em todo caso, as vacilações saussurianas e os remanejamentos dentro da proposta gerativista demonstram o quanto as questões em torno do sentido implicam aquelas em torno da subjetividade, não devendo, pois, ser acusado de anacrônico o encadeamento aristotélico entre fala e afecções de alma, ou seja, entre fala e campo da interioridade, em que pesem terem sofrido deslocamentos e contestações ao longo de séculos os postulados de Aristóteles acerca do conhecimento e das relações entre sujeito e coisa (ou objeto). Os próprios estatutos da coisa e do sujeito sofreram deslocamentos e contestações.

Se um bom livro de introdução à Filosofia deixa claros todos esses movimentos, uma leitura acurada do que se escreve a respeito não terá difículdades em perceber, todavia, ter-se algo mantido, do Pensamento Clássico até o advento da Psicanálise, em grande medida irredutivel, qual seja, a caracterização da sede do conhecimento como uma subjetividade cognoscente inalienável de si mesma: se, para Aristóteles, a faculdade do conhecimento é atributo da almat9, a psique, hoje, a disciplina que se ocupa propriamente do sujeito que conhece é denominada Psicologia Cognitiva.

4s CHOMSKY, Noam. Aspectos da teoria da sintaxe. 1978, p. 83.

(t) ABBAGNANO, 1982, p. 26. 


\section{REFERÊNCIAS BIBLIOGRÁFICAS}

ABBAGNANO, Nicola. Dicionário de filosofia. Trad. de Alfredo Bosi. 2. ed. São Paulo: Mestre Jou, 1982.

ALTHUSSER, Louis. Sobre a relação de Marx com Hegel. In: D'HONDT, Jacques et al. Hegel e o pensamento moderno. Trad. de Rui Magalhães. Porto: Rés, 1979.

BORDINI, Maria da Glória. Fenomenologia e Teoria Literária. São Paulo: Edusp, 1990.

CHOMSKY, Noam Avram. Aspectos da teoria da sintaxe. Trad. José António Meireles \& Eduardo Paiva Raposo. 2. ed. Coimbra: Arménio Amado, 1978.

DERRIDA, Jacques. Gramatologia. Trad. de Miriam Schnaiderman e Renato Janine Ribeiro. São Paulo: Perspectiva, 1973.

DERRIDA, Jacques. Margens da filosofia. Trad. de Joaquim Torres Costa \& António M. Magalhães. Campinas: Papirus, 1991.

DERRIDA, Jacques. O poço e a pirâmide: introdução à Semiologia de Hegel. In: D'HONDT, Jacques et al. Hegel e o pensamento moderno. Trad. de Rui Magalhães. Porto: Rés, 1979.

DESCARTES, René. Obra escolhida. Trad. de J. Guinsburg e Bento Prado Júnior. 2. ed. São Paulo: Difel, 1973. Meditações.

HEGEL, Georg Wilhelm Friedrich. Enciclopédia das ciências filosóficas em compêndio: 1830. Trad. de Paulo Meneses, com a colaboração de José Machado. São Paulo: Loyola, 1995. vol. 1.

HEGEL, Georg Wilhelm Friedrich. Enciclopédia das ciências filosóficas em compêndio: 1830. Trad. de Paulo Meneses, com a coloaboração de José Machado. São Paulo: Loyola, 1995, vol. 3.

HEGEL, Georg Wilhelm Friedrich. Estética. Trad. de Álvaro Ribeiro \& Orlando Vitorino. Lisboa: Guimarães Editores, 1993.

HEGEL, Georg Wilhelm Friedrich. Fenomenologia do espirito. Trad. de Paulo Meneses, com a colaboração de Karl-Heinz Efken. Petrópolis: Vozes, 1992, Parte I.

HENRY, Paul. A ferramenta imperfeita. Trad. de Maria Fausta Pereira de Castro. Campinas: Pontes, 1992. 
HUSSERL, Edmund. Ideas: general introduction to pure Phenomenology. Transl. by W. R. Boyce Gibson. London: George Allen \& Unwin, 1976.

KANT, Immanuel. Critica da razão pura. Trad. de Manuela Pinto dos Santos \& Alexandre Fradique Morujão. 2. ed. Lisboa: Fundação Calouste Gulbenkian. 1982.

SAUSSURE, Ferdinand de. Curso de lingüistica geral. Trad. de Antônio Chelini, José Paulo Paes \& Izidoro Blikstein. 15. ed. São Paulo: Cultrix, 1989. 